\title{
Air temperature gradient in large industrial hall
}

\author{
Michat Karpuk ${ }^{1}$, Aleksander Pełech ${ }^{1}$, Edward Przydróżny ${ }^{1}$, Juliusz Walaszczyk ${ }^{1}$, \\ and Sylwia Szczęśniak ${ }^{1, *}$
}

${ }^{1}$ Wroclaw University of Science and Technology, Faculty of Environmental Engineering, ul. Norwida 4/6, 50-370 Wroclaw, Poland

\begin{abstract}
In the rooms with dominant sensible heat load, volume airflow depends on many factors incl. pre-established temperature difference between exhaust and supply airflow. As the temperature difference is getting higher, airflow volume drops down, consequently, the cost of AHU is reduced. In high industrial halls with air exhaust grids located under the ceiling additional temperature gradient above working zone should be taken into consideration. In this regard, experimental research of the vertical air temperature gradient in high industrial halls were carried out for the case of mixing ventilation system The paper presents the results of air temperature distribution measurements in high technological hall (mechanically ventilated) under significant sensible heat load conditions. The supply airflow was delivered to the hall with the help of the swirl diffusers while exhaust grids were located under the hall ceiling. Basing on the air temperature distribution measurements performed on the seven pre-established levels, air temperature gradient in the area between 2.0 and $7.0 \mathrm{~m}$ above the floor was calculated and analysed.
\end{abstract}

\section{Introduction}

To calculate of volume airflow in mechanical ventilation systems, it's necessary to establish maximum allowed air temperature increase between air supply and exhaust zone. This issue is quite easy for the rooms with relatively low height $(\mathrm{h} \leq 4 \mathrm{~m})$ and for the rooms where exhaust element is located in users' operating zone. It's much more complicated in the higher rooms $(\mathrm{h}>4 \mathrm{~m})$, where exhaust elements are located near the ceiling. The reason for this is potential temperature change along with the height of the room. Too small temperature increase assumed for calculations will result in unreasonable air volume and its treatment necessity. On the other hand, when temperature increase over operating zone (without impairing conditions in this zone) will be taken into account, lower air flow rates will be necessary for ventilation (resulting in air treatment costs reduction). This problem is crucial in rooms where due to constructional or technological requirements, air must be blown from the top of the room and exhaust grids are high above occupied zone.

Vertical air temperature gradient in occupied zone is one of the most important factors defining thermal comfort [1]. There are numerous publications related to temperature stratification in the operating zone $[1,2,5,7,8]$. Research results of the operating zone are available to provide best possible conditions for the people and technology used in the room. 
From energy consumption point of view, it's more important to estimate maximum temperature gain in the entire room than the difference between exhaust and supply air temperature. Obviously we have to provide appropriate conditions in the operating zone. Air temperature increase over the operating zone $(\theta)$ is closely related to the issue described as room average temperature gradient $(\delta \mathrm{t})$. Discussed issue was not described satisfactory for higher rooms $(h>4 \mathrm{~m})$ with significant heat load.

\section{Theory}

\subsection{Air flow rate calculation}

Mechanical HVAC systems serving rooms with dominant sensible heat load and required air flow rate depends on the sensible heat load value and maximum value of temperature increase between exhaust air and supply air zones. Air volume can be calculated using following equation :

$$
V=\frac{Q_{s h l}^{\max }}{\rho \cdot c_{p} \cdot \Delta t^{\max }}=\frac{Q_{S h l}^{\max }}{\rho \cdot c_{p} \cdot\left(t_{e}-t_{S}\right)^{\max }}
$$

where: $V$ - air flow rate; $\mathrm{m}^{3} / \mathrm{s}, Q_{s h l}^{\max }$ - maximum sensible heat load in the room, $\mathrm{kW}, \rho$ - air density; $\mathrm{kg} / \mathrm{m}^{3}, c_{p}$ - air specific heat capacity; $\mathrm{kJ} / \mathrm{kgK} ; t_{s}, t_{e}-$ supply and exhaust air flow temperatures,${ }^{\circ} \mathrm{C}$;

Temperature increase $\Delta t^{\max }$ for air flow volume in high rooms with dominant sensible heat load can be expressed in the slightly different form:

$$
\Delta t^{\max }=\left\{\left[t_{o z}+\delta t\left(h_{e}-h_{o z}\right)\right]-t_{s}\right\}^{\max }
$$

where: $t_{o z}, t_{s}$ - occupied zone air temperature, supply air temperature, ${ }^{\circ} \mathrm{C} ; h_{e}, h_{o z}$ - elevation of exhaust grids and occupied zone, $\mathrm{m} ; \delta t$ - average vertical air temperature gradient over operating zone, $\mathrm{K} / \mathrm{m}\left({ }^{\circ} \mathrm{C} / \mathrm{m}\right)$.

\subsection{Vertical air temperature gradient over occupied zone}

Average air temperature gradient in the room $(\delta t)$ is the air temperature change along with the elevation, related to the distance from agreed baseline (usually floor level) measured perpendicularly to this baseline $[2,5,6]$. It's expressed in $\mathrm{K} / \mathrm{m}$. In this article, we set baseline at the level of $2 \mathrm{~m}$ (theoretical height of operating zone). Average air temperature gradient can be calculated using below formula :

$$
\delta t=\frac{\theta}{h_{e}-h_{o z}}=\frac{t_{e}-t_{o z}}{h_{e}-h_{o z}} ; \frac{K}{m}
$$

where: $\Theta$ - air temperature increase above operating zone, $\mathrm{K} ; t_{e}, t_{o z}-$ air temperature above occupied zone $\left(h_{e}\right)$ and occupied zone air temperature, ${ }^{\circ} \mathrm{C}$. Illustration of relationships $(1$, 2 and 3 ) are presented in Figure 1. 


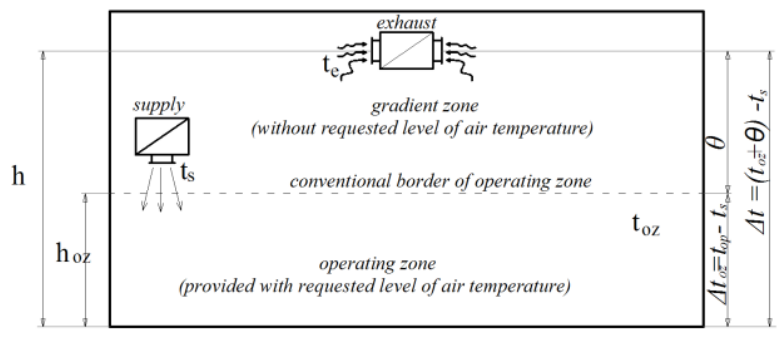

Fig.1. Illustration of symbols and assumptions for formulas 1-3.

There are two zones in rooms with dominant sensible heat load. The first one - operating zone - should be provided with the requested level (or range) of air temperature. This demand comes from an expected thermal comfort or technological expectations. This demand is connected with thermal comfort and/or technological requirements. The second one - let's call it transitional - exists over operating zone where we don't expect to keep thermal requirements. In this zone we may observe thermal stratification and additional temperature increase. Part of the sensible heat load coming from electrical lights, technology, walls and windows can be transferred into this zone through natural convection. Basing on available literature $[1-3,7,9]$ additional temperature increase can be estimated.

Temperature increase above operating zone $(\Theta)$ is:

$\checkmark$ directly proportional to room specific heat load $\left(q=\frac{Q_{s h l}}{a \cdot b \cdot h} ; \frac{W}{m^{3}}\right)$ and share of the heat generated in the room or transferred to the room over operating zone within total room heat load $\left(\frac{Q_{s h l}^{h_{o z} \div h_{e}}}{Q_{z b j}}\right)$,

$\checkmark$ inversely proportional to room air change rate $\left(\psi=\frac{V}{a \cdot b \cdot h}\right)$ and heat sources surface ratio within total room surface $\left(\frac{\Sigma a}{A}\right)$.

Fig.2. presents changes of average air temperature gradient in the function of distance from the operating zone, calculated according to the guidelines presented in $[2,5]$. The conclusion from this chart is : average temperature gradient decreases with the distance from the operating zone.

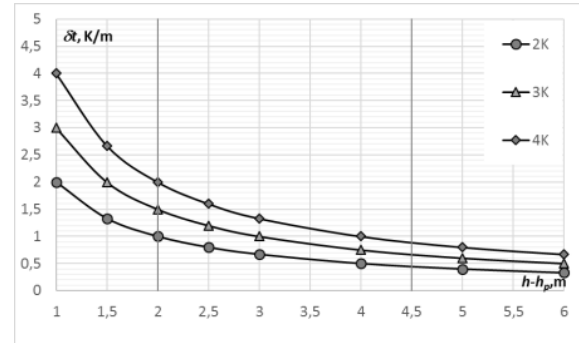

Fig. 2. Average room temperature gradient in function of the distance from operating zone (height difference $h-h_{o z}$ ) for different values of temperature increase $\Theta$. 


\section{Facility and research methods}

\subsection{Building architecture}

Facility chosen for the research was a technological hall located in the northern part of Wroclaw. Examined building has got only two external surfaces: roof and eastern wall. External walls $550 \mathrm{~mm}$ thick are made from foam concrete bricks without additional thermal insulation. Hall floor is directly based directly on the ground. Steel roof construction was designed in the cylinder shape. There are four bowed sky roof points $3 \times 10 \mathrm{~m}$ size, made from partially transparent panels. Gate $2.6 \times 3.3 \mathrm{~m}$ size is situated in the external wall.

At the roof/wall joints there are 26 glow discharge tubes. Additionally, under the ceiling there are 24 halogen lamps situated over transportation paths. There are 29 injection moulding machines $4.3 \times 1.2 \times 2.0 \mathrm{~m}$ each. There are maximum 18 operators working in the hall. The hall is equipped with mixing ventilation system without air cooling capability.

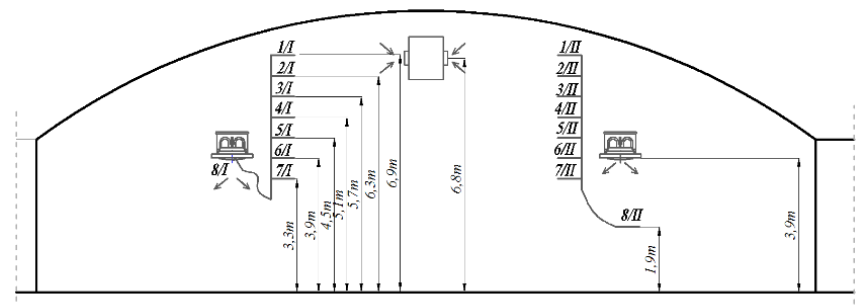

Fig. 3. Location of supply air diffusers and exhaust grids in the examined hall including the layout of air temperature measurement points.

\subsection{Thermal characteristics}

Dominant pollution emitted in the hall is heat, mentioned in the article as sensible heat. For the purpose of this article the sensible heat balance of the hall during summer and winter season was calculated using the method described in [5]. Sensible heat balance calculation was carried out for July, September and for different ambient temperatures of winter season under different ambient air temperature conditions. Sensible heat balance calculation was used to lead initial vertical air temperature stratification and location of measurement points. Table 2 presents basic hall data.

Table 2. Examined hall data.

\begin{tabular}{|c|c|c|}
\hline Hall space & $\mathrm{m}^{3}$ & 12351 \\
\hline Floor surface area & $\mathrm{m}^{2}$ & 1774,5 \\
\hline Roof surface area & $\mathrm{m}^{2}$ & $1897 / 120$ \\
\hline Ventilation type & & No cooling \\
\hline Maximum ventilation air volume air flow rate & $\mathrm{m}^{3} / \mathrm{h}$ & 100000 \\
\hline Maximum air change ratio in the hall. & $\mathrm{h}^{-1}$ & 5,8 \\
\hline Range of specific sensible heat load value in the hall & $\mathrm{W} / \mathrm{m}^{3}$ & $7-13$ \\
\hline $\begin{array}{c}\text { Share of heat load from sources located in the } \\
\text { operating zone in total sensible heat balance }\end{array}$ & $\%$ & 90 \\
\hline $\begin{array}{c}\text { Share of heat load coming from the roof and sky } \\
\text { roof panels }\end{array}$ & $\%$ & 10 \\
\hline \begin{tabular}{c} 
(n) \\
\hline
\end{tabular} & & \\
\hline
\end{tabular}

\subsection{Description of measurement station}

To provide the best possible measurement results the special measurement, with 8 temperature sensors mounted on the each post, was built in industrial hall. One of the sensors on the post had 
adjustable position, other seven sensors had fixed position with gauge of $60 \mathrm{~cm}$. Figure 3 shows configuration of measurement station and numbering of the sensors including vertical dimension of the position of sensors. Sensor 8/I was used to measure the temperature of supplied air, sensor 8/II was measuring temperature in operating zone. Measurements were done between April 2014 and August 2014. Posts were located in the most representative spots. Initial measurements indicated locations where ventilation system worked inefficiently or was too intensive.

Temperature measurements were done every 10 minutes using sensors PT1000 class A with measurement accuracy of $0.15^{\circ} \mathrm{C}$.

\section{Results and discussions}

\subsection{Air temperature in technological hall}

Fig.4. and Fig.5. present air temperature changes and average air temperature gradient observed in April 2014 (Fig. 4) and in July and August (Fig. 5) 2014. Charts present air temperature changes in the operating zone (sensor $8 / \mathrm{II}$ ), temperature near exhaust points (sensor 1/I, 1/II) and temperature nearby air supply points. (sensor 8/I). For clarity of the chart, sensors located in transition zone were not presented.

In April 2014 temperature increase value in the operating zone was approximately at the level of $6^{\circ} \mathrm{C}$ and it was the highest during the entire measurement session. Lowest temperature of supply air flow was about $18^{\circ} \mathrm{C}$. During this period, temperature in the operating zone was at the level of $26^{\circ} \mathrm{C}$ and temperature of exhaust air was at the level of $29^{\circ} \mathrm{C}$. Average air temperature gradient in the hall $(\delta \mathrm{t})$ was $0.7 \mathrm{Km}^{-1}$.

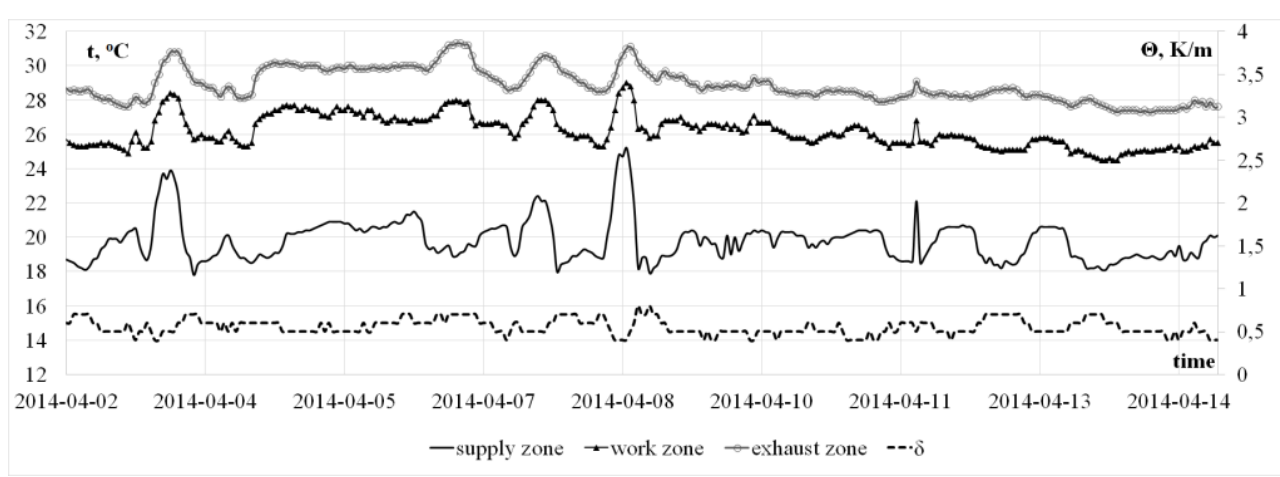

Fig. 4. Air temperature and average temperaure gradient in the hall in April 2014.

Temporary increase of supply air flow temperature (caused by ambient air temperature increase) was resulting in temperature increase in the operating zone and exhaust air. At the same time $\Theta$ value was dropping and, as a consequence, average temperature gradient value $\delta$ t was also decreasing. In April 2014 supplied air temperature resulted from the heating of the mixture of fresh and recirculated air, so constant air temperature in the operating zone was provided. In July and August 2014 average air temperature increase was at the level of $1.8 \mathrm{~K}$ and this was the lowest value during entire measurements. The lowest supply air flow temperature was $22.9^{\circ} \mathrm{C}$. During this period air temperature in the operating zone was $25^{\circ} \mathrm{C}$ and exhaust air temperature was $28^{\circ} \mathrm{C}$. Average temperature gradient was $0.6 \mathrm{Km}^{-1}$. The highest difference, in comparison to the April session, was visible in the significant temperature oscillation depending on the time of the day/night. The reason for those variations was no air cooling capability so practically supply air temperature was equal to current ambient temperature. 
Fig. 5. shows the temperature variation during July/August 2014. Increase of the supply air temperature was directly resulting in increase of the temperature in the operating zone and exhaust air measurement points. Increasing air temperature in the hall resulted in the smaller temperature growth above operating zone and lower value of average air temperature gradient in the hall.

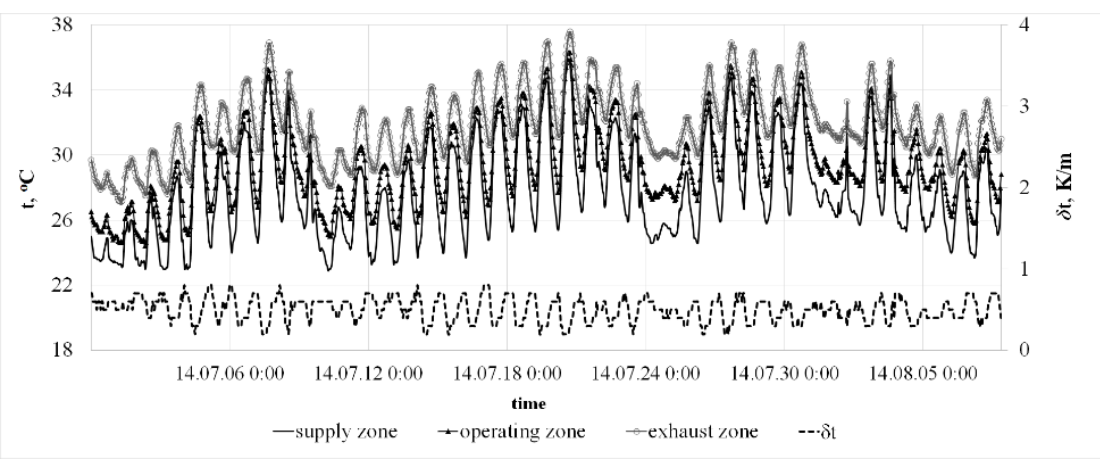

Fig. 5. Air temperature and average air temperature gradient in the hall during July and August 2014.

Fig. 6 and Fig. 7 show air temperature and gradient variations for two selected days in April and two selected days in July.

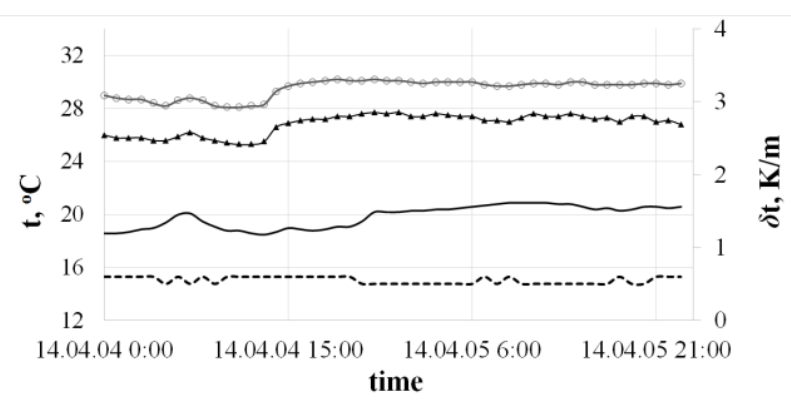

-supply zone $\rightarrow$-operating zone $\quad-$ exhaust zone $\quad-\cdots \delta \mathrm{t}$

Fig. 6. Air temperature and average air temperature gradient in the hall on 4th and 5th April 2014.

Both charts confirm that in April air temperature in the hall was almost constant. This was caused by the treatment (heating) of fresh and recirculated air flow mixture. During July/August air temperature in the hall was directly depending on the ambient temperature. Variations between day and night are clearly visible on the charts. It can be noticed that along with the growth of supply temperature the average air temperature gradient in the operating zone decreases. This applies also to the transition zone (above operating zone) air temperature. 


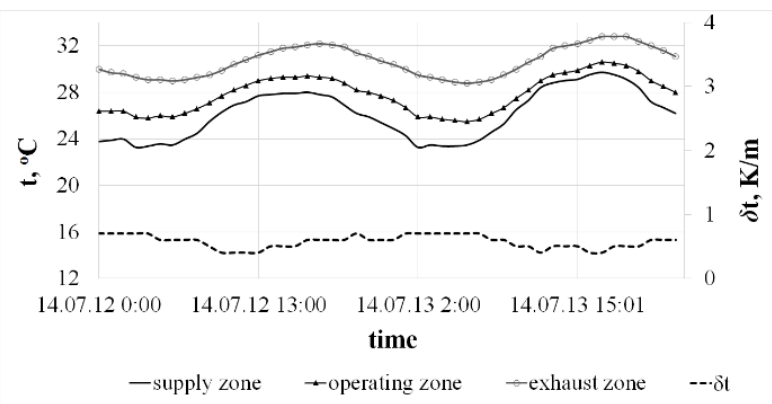

Fig. 7. Air temperature and average temperature gradient in the hall on 14th and 15th July 2014.

Relationship between air temperature increase in the hall $(\Delta t)$ and temperature increase in operating zone $\left(\Delta t_{o z}\right)$ is presented in Fig.8. The chart includes all values of $\Delta t\left(\Delta t=t_{e}-t_{s}\right)$ for the different increases of $\Delta t_{o z}$. Higher temperature in the operating zone resulted in the higher total temperature increase in the hall.

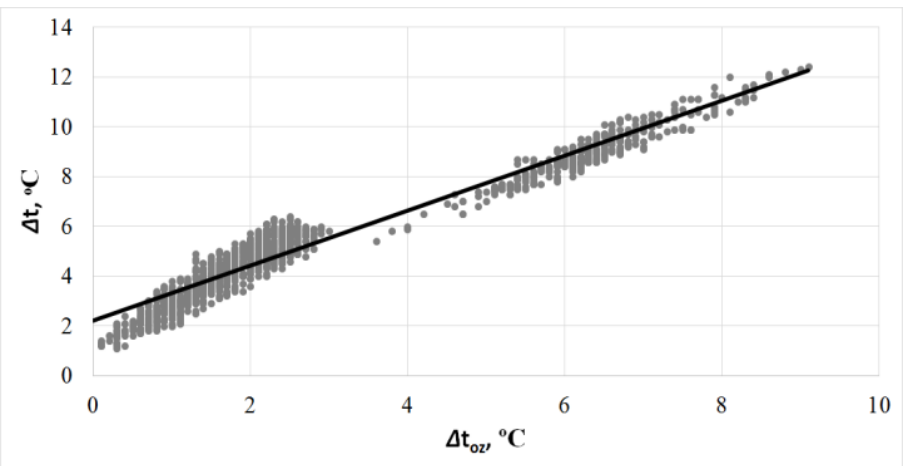

Fig. 8. Temperature increase in operating zone in function of temperature increase in the hall.

Fig. 9 presents relationship between average air temperature gradient in the hall $(\delta t)$ and supply air temperature $\left(t_{s}\right)$. In this case we've observed inversely proportional relationship which was confirmed in the charts in Fig. 4-Fig. 7. Statistically this relationship is not firm but in our opinion it takes place. Possibly it might have been caused by an uncontrolled variation in air volume made by hall operators. This conclusion needs further research to be fully confirmed.

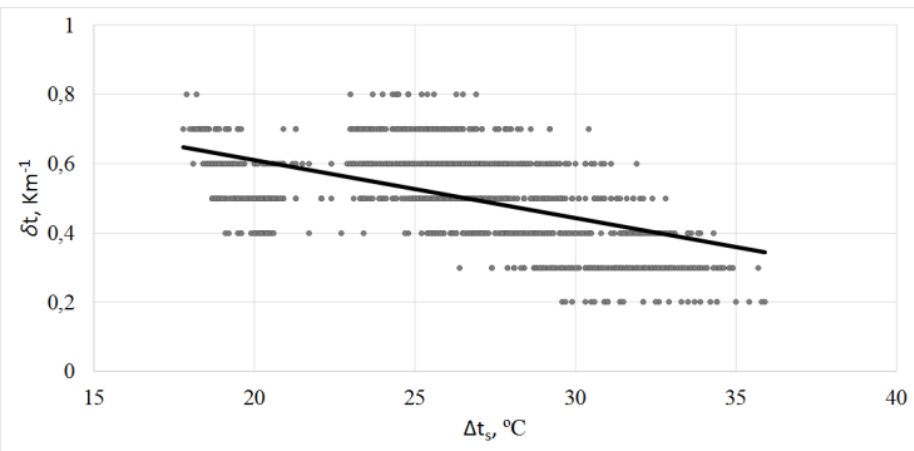

Fig. 9. Average temperature gradient in the hall related to supply air temperature. 
In Fig. 10. we present temperature changes at different hall elevation in relation to air temperature and temperature increase in the operating zone. Quick air temperature change in relation to the distance from operating zone takes place within $2 \mathrm{~m}$ above this zone. Four metres above floor level the air temperature stabilises and temperature increase is minor. Such dependence was previously described [2,3,7-9]. The higher was the temperature in the operating zone, the higher was the temperature in the highest hall point, however technological sensible heat load at that time had the lowest value during the whole year.

Fig. 11. presents variability of average air temperature gradient in relation to the distance from the operating zone. Presented nature of variability of $\delta$ t stays in the relationship with characteristics presented in Figure 2. Major drop of $\delta$ t value is observed within $1.5-3.0 \mathrm{~m}$ from the operating zone. At more than $4 \mathrm{~m}$ above the floor, the intensity of value change is dropping.

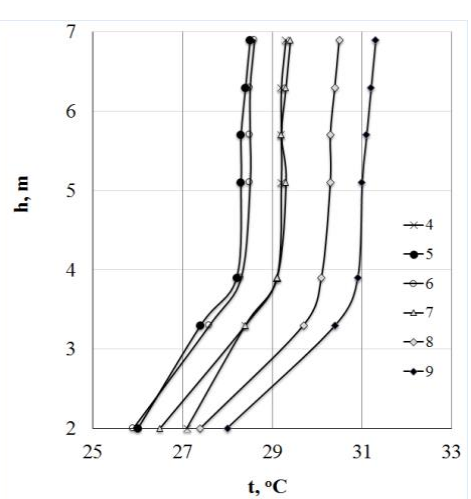

Fig. 10. Air temperature change at different elevation in relation to air temperature and temperature increase in the operating zone.

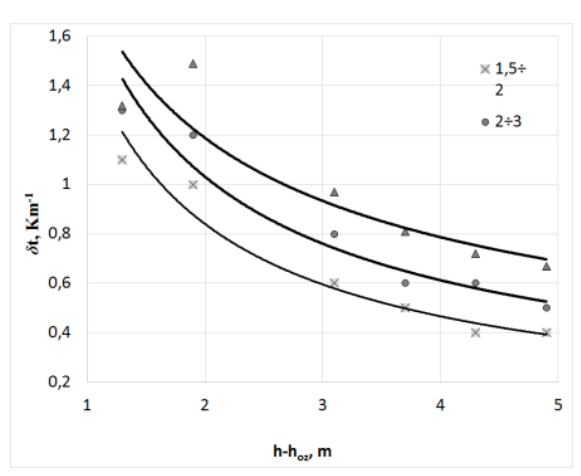

Fig. 11. Average temperature gradient in dependence with distance from the operating zone.

\section{Conclusions}

1. Air temperature stratification in the hall appears during minimum and maximum heat load in the hall.

2. Relationship between the hall air temperature increase and air temperature increase in the operating zone was determined. This relationship gives an opportunity for easier estimation of the air temperature increase, necessary for air flow rate calculation in the halls with similar technological and thermal features for AHU without air cooling treatment.

3. Average air temperature gradient is inversely proportional to supply air temperature where during summer time ambient air or ambient/recirculated air is blown into the hall.

4. Significant air temperature growth over operating zone appears within $2 \mathrm{~m}$ distance. Above this line, temperature increase is minor.

This publication presented data obtained under the research project "Air temperature gradient in mechanically ventilated rooms with mixing ventilation" Nr N523 748040 funded by National Science Centre of Poland.

\section{References}

1. H. Awbi, Ventilation of building (London and New York: Spon Press, 2003) 
2. V.V. Baturin, Osnowy promyschlennoj ventilacii (Pofizdat, Moskva, 1990)

3. H. Goodfellow, E. Tahti, Industrial Ventilation (Academic Press, 2001)

4. T. Hayashi, R.H Howell, M. Shibata, K. Tsuji, Industrial Ventilation and Air Conditioning (CRC Press Inc, Boca Raton, Boston, 1985)

5. A. Pełech, Wentylacja i Klimatyzacja. Podstawy (Oficyna Wydawnicza Politechniki Wrocławskiej, 2009)

6. S. Przydróżny, Wentylacja (Wydawnictwo Politechniki Wrocławskiej, 1991)

7. M. Xu, T. Yamanaka, H. Kotani, Indoor Air 11, 2 (2001)

8. T. Gil-Lopez, M.A. Galvez-Huerta, P.G O’donohe, J. Castejon-Navas, P.M Dieguez-Elizondo, Energ. Buildings 140, 371 (2017)

9. B. Iskandriawan, Energ. Buildings 21, 2 (2010) 